\title{
EXPERIMENTS AND FINITE ELEMENT ANALYSIS OF GEOSYNTHETICS REINFORCED RESIDUAL SOIL
}

\author{
Syed Abdul Mofiz ${ }^{1}$, Member ASCE and Fellow IEB, \\ Mohd. Raihan Taha ${ }^{2}$, Member IEM, and Md. Mizanur Rahman ${ }^{3}$, Member IEB
}

\begin{abstract}
The study investigates possible effects of stress path on a series of consolidated-drained triaxial compression and extension tests. Test reaults of unreinforced and reinforced residual soil simulating the different loading path similar to what is expected in the field. The testing program concentrated on the study of normally consolidated on $100 \mathrm{~mm}$ diameter and $200 \mathrm{~mm}$ high specimens. Testing was carried out at consolidating pressures ranging between $0.10-0.60 \mathrm{MPa}$ using GDS computer control triaxial apparatus. The Cam-Clay model parameters for unreinforced and reinforced residual soil were determined based on isotropically consolidation and drained shear test results. Computations were performed using the model constant and finite element software SIGMA/W to predict the stress-strain response for different consolidation pressure and stress path tests. Predicted results were compared with measured response to assess the validity of the model parameters. The model prediction was found to yield acceptable results and is quite effective in demonstrating the effects of stress paths, effective stresses and strains of reinforced soil composites.
\end{abstract}

\section{INTRODUCTION}

One of the indigenous discoveries in this century in the field of geotechnical engineering is the concept of "reinforced earth". This concept has quickly attracted the attention of practicing engineers and researchers all over the world. The use of

\footnotetext{
${ }^{1}$ Associate Professor, Department of Civil Engineering, Rajshahi University of Engineering \& Technology, Rajshahi 6204, Bangladesh, samofiz@hotmail.com.

${ }^{2}$ Professor, Department of Civil \& Structural Engineering, Universiti Kebangsaan Malaysia, UKM Bangi 43600, Selangor, Malaysia, drmrt@ vlsi.eng.ukm.my.

3 Lecturer, Department of Civil Engineering, Rajshahi University of Engineering \& Technology, Rajshahi 6204, Bangladesh, mizan95012@yahoo.com.
} 
geosynthetics as a reinforcement potentially increases the bond between soil and reinforcement. Reinforced soil has been used in various geotechnical structures including retaining walls, foundations, pavements and embankments. Due to the wide applications, reinforced soil is subjected to different loading conditions. Since field tests are very costly, it is essential to predict the strength deformation behaviour of reinforced residual soil based on laboratory tests. These tests are also commonly used to assess design parameters for its intended use. The aim of this study is to investigate the strength-deformation characteristics and failure mechanism of unreinforced and geosynthetics reinforced residual soil. This study will provide a better understanding of the composite geosynthetic reinforced in residual soil. There have not been many researches on the use of residual soils in reinforced earth stnctures. Since residual soils are the major soil materials found in tropical climates, its use a construction material will optimise costs. Thus it is apparent that the advantages of both materials, i.e. geosynthetics and residual soils need to be fully tapped and exploited. In the recent past many constitutive models have been proposed to characterize the behaviour of soils. These models are based on nonlinear elasticity, plasticity and elasto-plastic theory. The importance of soil models has been enhanced significantly with the great increase in development and application of computer-based techniques such as the finite element method. This method usually involves a number of material constants and use of a number of advanced laboratory tests under various stress paths, often using multiaxial devices. Determination of constitutive model parameters or calibration of the model is a very important step in modelling of geotechnical problems. Thus, a thorough investigation is made to determine model parameters and illustrate the model characteristics of stress-strain and volume change of reinforced soil under six stress paths. The CamClay model constants were obtained from this study. The stress-strain prediction characteristics were made using model constants and finite element method. Finally, the verification of the model parameters has been made from the test results.

\section{SOIL AND REINFORCEMENT}

Residual soils often found in tropical or semi-tropical area, are formed from intense weathering of rocks under consistently high temperature and rainfall. In this work, the disturbed soil was collected from the tropical or semi-tropical area. The soil is reddish in color and classified as $\mathrm{CH}$ in the Unified Classification System (USCS). The soil contains about $45 \%$ clay, $19 \%$ silt, and $36 \%$ sand. The maximum dry density from the standard Proctor test was $14.42 \mathrm{kN} / \mathrm{m}^{3}$ and the optimum moisture content was about $24.6 \%$. In this research work, a non-woven geotextile was used as the reinforcement material. This group of geotextiles consists of mechanically bonded continuous filaments made from UV-stabilized polypropylene. The tensile strength properties of the reinforcement were determined following ASTM D4595 (ASTM 2000). The maximum tensile strength from the tests was obtaned 18.68 $\mathrm{kN} / \mathrm{m}$ and $19.12 \mathrm{kN} / \mathrm{m}$ in the longitudinal and transverse direction, and the corresponding elongations were about $74 \%, 51 \%$ respectively. 


\section{TEST PROCEDURE}

In this investigation, six consolidated drained triaxial stress path tests were performed on the unreinforced and reinforced residual soil. The testing programs are divided into two phases, i.e., triaxial compression stress path and triaxial extension stress path. The stress path tests are Conventional Triaxial Compression (CTC); Conventional Triaxial Extension (CTE): Reduced Triaxial Compression (RTC); Reduced Triaxial Extension (RTE); Triaxial Extension (TE); Triaxial Compression (TC) and Hydrostatic Compression (HC). All of these stress paths are presented in Figure 1. The stress path tests were followed using $100 \mathrm{~mm}$ dia and $200 \mathrm{~mm}$ high cylindrical triaxial specimen for both unreinforced and reinforced soil. Based on the unit weight and the volume of the triaxial mold, the total weight of the soil was divided into three equal portions and compacted inside the mold in layers of equal height. For reinforced specimen, two circular discs of non-woven geotextile were placed at the $1 / 3$ height from the top and $1 / 3$ height from the bottom of the specimens. A rate of $0.15 \mathrm{~mm} / \mathrm{min}$ for compression on a triaxial press was adopted, and each layer was compacted following the approach by Cui and Delage (1996) to ensure Proctor maximum density with a double piston system. The tests reported in this paper for both unreinforced and reinforced soil were carried out under consolidation pressure in the range $100-600 \mathrm{kPa}$. A strain rate of $0.0015 \% / \mathrm{min}$ was used to ensure no pore pressure change as required in a drained test. The computer controlled triaxial (GDS) system was adapted to carry out all the stress path tests. The schematic diagram photographic views of the GDS triaxial system are shown in Figure 2 and Figure 3. A microprocessor collects the data from transducers automatically at prescribed intervals. The data were transmitted by the microprocessor for recording, processing and production of results, which could be displayed on the screen.

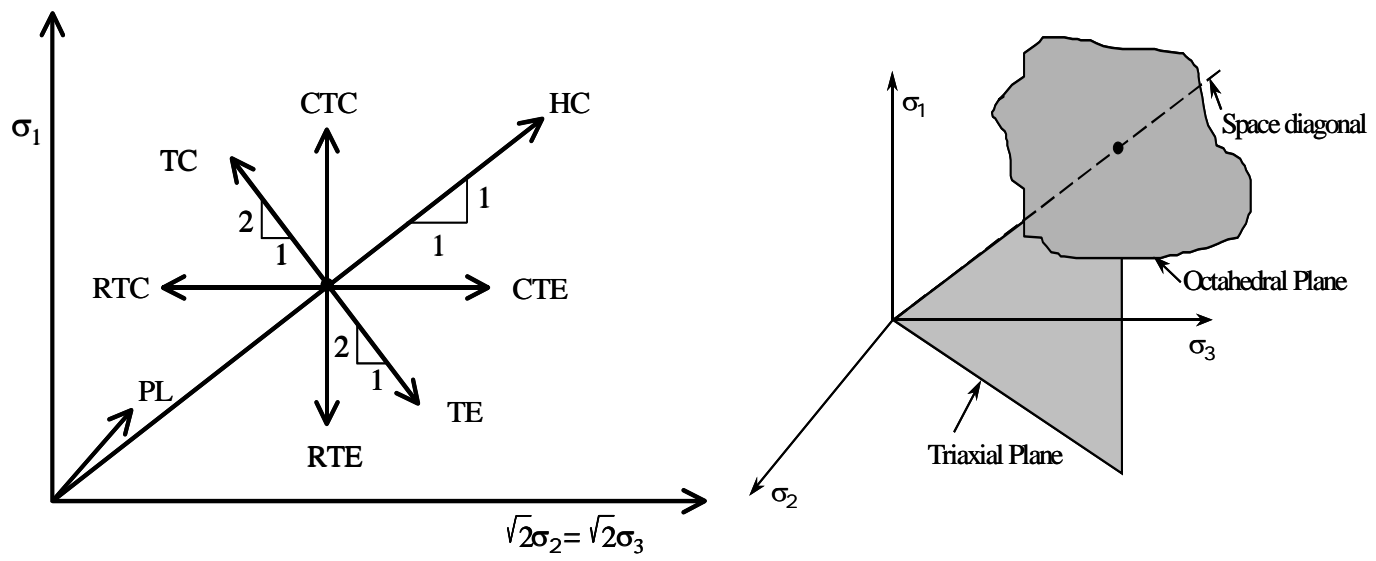

FIG.1. Representations of various stress paths on triaxial plane 


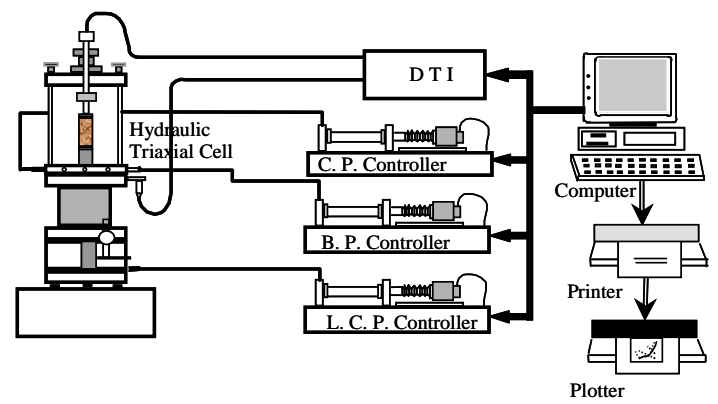

FIG.2. GDS triaxial testing system for stress path tests (after Mofiz, 2000)
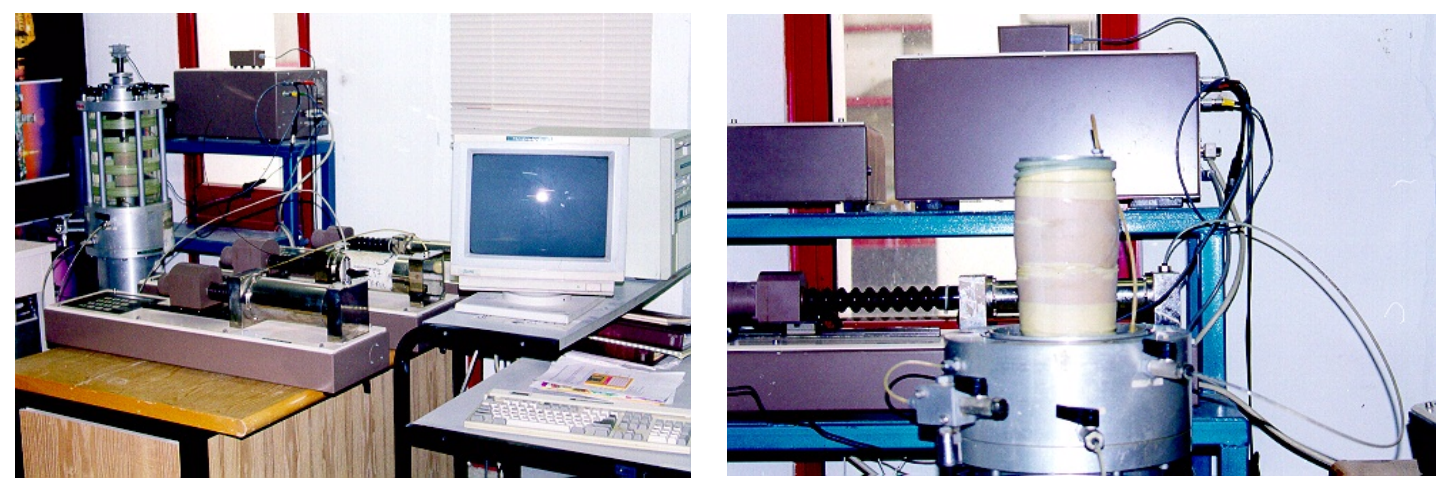

FIG.3. Photographic view of GDS triaxial testing system and failure pattern of a two layered reinforced soil specimen for CTC stress path for stress path tests

\section{TEST RESULTS AND DISCUSSION}

In this investigation, six triaxial compression and extension stress path tests, i.e. CTC, TC, RTC, CTE, TE, and RTE were conducted for unreinforced and reinforced residual soil. The shear stress versus axial strain and volumetric strain versus axial strain for the (CTC) stress paths at consolidation pressures $\left(\sigma_{c}\right)$ of $100 \mathrm{kPa}$ to 600 $\mathrm{kPa}$ are shown in Figure 4. The test results shows that the stress-strain relationships are non-linear and the failure strain increases with the increase in confining pressure for all the stress paths. It was observed that there were no distinct peak points in the $\sigma-\varepsilon$ curves. The curves levels off at higher strains until failure. The volume change characteristics for the conventional triaxial compression (CTC) path exhibits contraction behaviour at lower stress levels and expansion at higher stress levels. The shear stress-axial strain plot indicates that the axial strain corresponding to maximum shear stress increases with confining pressure. The shear stress versus axial strain and volumetric strain versus axial strain for the (CTE) stress paths at consolidation pressures $\left(\sigma_{c}\right)$ between $100 \mathrm{kPa}$ to $400 \mathrm{kPa}$ are shown in Figure 5. As in the case of compression loadings, the stress-strain relationships are non-linear and the failure strain increases with the increase in confining pressure for all the stress paths. Similarly, the $\sigma-\varepsilon$ curves do not produce any distinct peak points. The volume change characteristics for the conventional triaxial extension (CTE) path exhibit 
contraction volume change behaviour at lower stress levels and the rate of contraction decreases at higher stress levels. In these cases, the volume contraction is more noticeable than other stress paths. The main reason of this behaviour may be due to gradual increase of confining pressure until failure. The TE stress path test results show significantly lower volume contraction than CTE stress path. On the other hand, for RTE stress path the volume expansion increases at lower stress level and the rate decreases at higher stress level. Taha et al. (1999) reported similar behaviour in drained triaxial extension test on residual granite soil. Thus, the failure stress and the volume change behaviour for triaxial extension tests are also stress path dependent. The failure of the test specimens is observed at the mid height due to necking for all the triaxial extension tests. The result shows different volumetric pattern at higher strain when the soil samples started to dilate. From the test results it is also observed that the volumetric strain versus axial strain behaviour revealed that expansion is more pronounced especially at lower confining pressure. The results of decomposed granite soil samples also show that dilatancy is dependent on the confining pressure. In comparison of compression and extension stress path tests, the stress-strain and volume change plots of unreinforced and reinforced residual soil for the different stress paths at consolidation pressure $\sigma_{c}=100 \mathrm{kPa}$ are presented in Figure 6 and 7. At low stress levels the volume change characteristics exhibit volume contraction for CTC stress path whereas expansions for RTE stress path. This contraction-expansion behaviour is the result of the gradual increase of axial stress and decrease of axial stress with constant confining pressure. As one moves from CTC path to RTC path, the volume change contraction decreases and the soil starts expansion even at low stress levels. This phenomenon is most likely due to decreasing confining pressure and dependent on the stress path followed. Test observations of CTE paths indicate that the volume contraction is higher due to the gradual increase of cell pressure whereas expansion behaviour was observed for RTC paths. The volume contraction decreases for TE whereas expansion behaviour was observed for TC paths. This contraction-expansion behaviour for TC path is the result of the gradual increase of axial stress and incremental decrease of confining pressure and contraction behaviour happen due to increase of confining pressure.
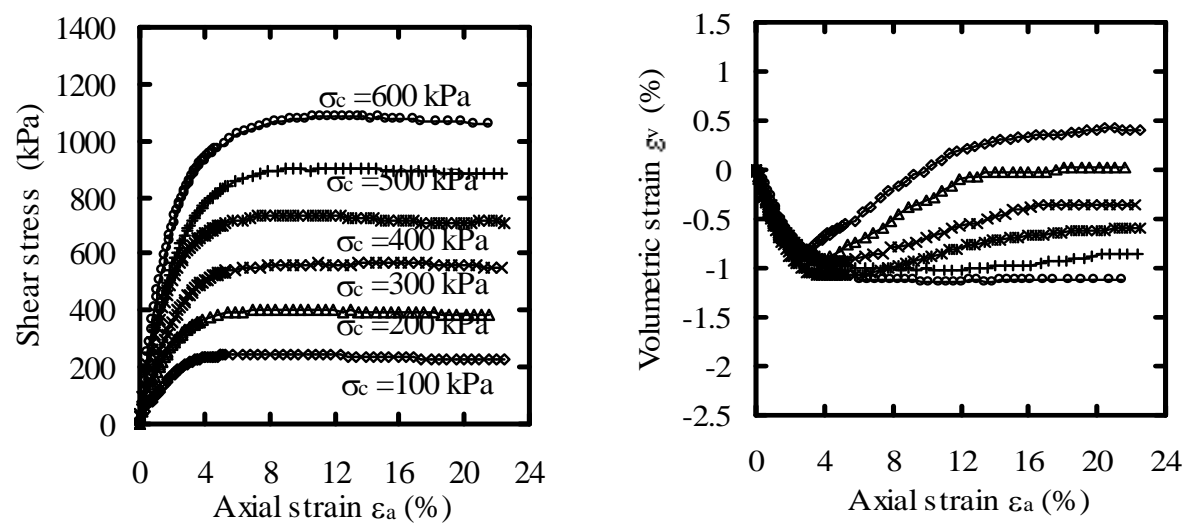

FIG.4. Shear stress and volumetric strain characteristics of residual soil for CTC (conventional triaxial compression) stress path 

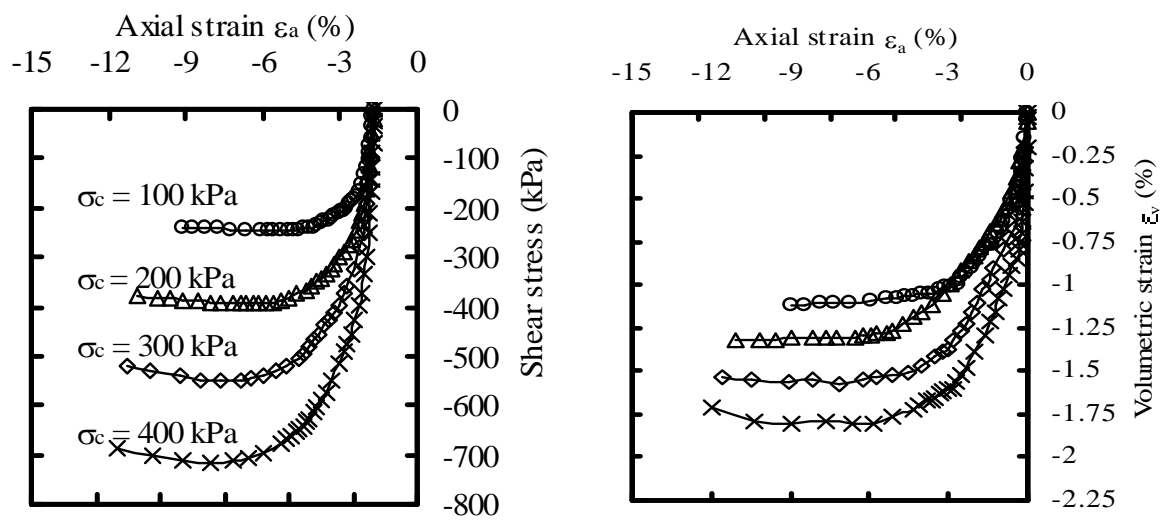

FIG.5. Shear stress and volumetric strain characteristics of residual soil for CTE (conventional triaxial extension) stress path
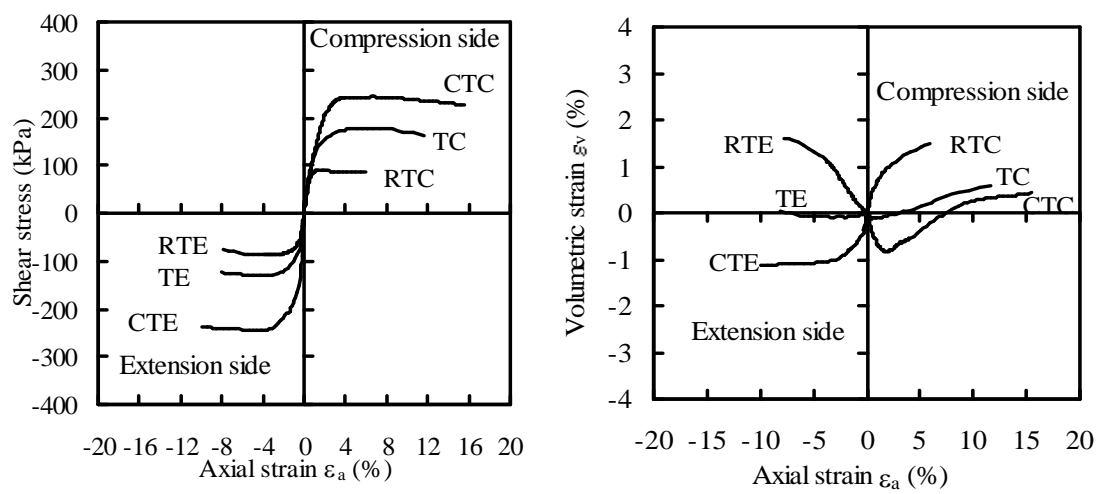

FIG.6. Behaviour of residual soil at consolidation pressure $\left(\sigma_{c}=100 \mathrm{kPa}\right)$ for different stress paths
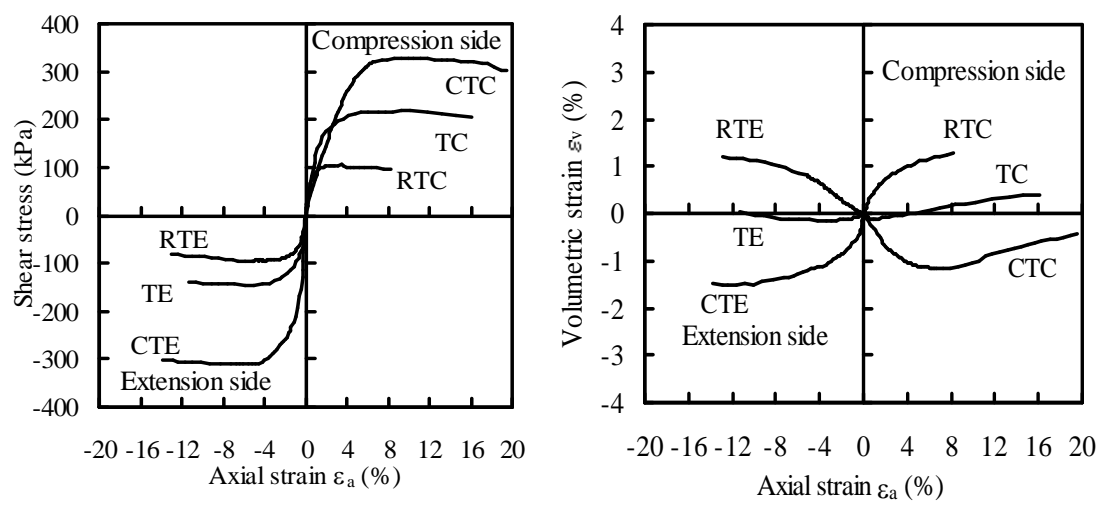

FIG.7. Behaviour of reinforced residual soil at consolidation pressure $\left(\sigma_{\mathrm{c}}=100 \mathrm{kPa}\right)$ for different stress paths

In this research, it is observed that the cohesion intercept and the angle of internal friction of the residual soil for the compression stress path are higher than that for the extension stress path. This increase in mobilised shear strength may be higher due to the soil particles try to reconsolidate under compression loading. For extension paths, it has slightly lower values because the shear load is applied in the lateral or reverse 
direction which may cause soil to fail under tensile forces. Test results show that the shear parameters are slightly different in compression and extension loadings. The effective cohesion and angle of internal friction of soil under compression and extension loading are $c^{\prime}=27.42 \mathrm{kPa}, \phi^{\prime}=28.02^{\circ}$ and $\mathrm{c}^{\prime}=23.50 \mathrm{kPa}, \phi^{\prime}=27.00^{\circ}$ respectively. For reinforced soil, the effective shear parameters under compression and extension loading are $c^{\prime}=43.85 \mathrm{kPa}, \phi^{\prime}=32.4^{\circ}$ and $\mathrm{c}^{\prime}=38.56 \mathrm{kPa}, \phi^{\prime}=30.81^{\circ}$ respectively. It is also observed that the reinforced soils exhibit higher failure strain and shows about $20 \%$ to $43 \%$ higher than that of unreinforced soils.

\section{MODEL CONSTANTS}

The Cam-Clay model was used for this study as the constitutive model to define the stress-strain properties of the soil skeleton in terms of effective stresses. The CamClay model is an elasto-plastic stress-strain model for soil that was originally developed by Roscoe (Roscoe and Schofield, 1963), and later modified by Roscoe and Burland (1968). The five parameters are illustrated in Figure 8. The critical state line shown in the $p^{\prime}-q$ plane is the locus of critical states projected onto that plane. Determination of the Cam-Clay model parameters are made based on the critical state concepts. Hydrostatic compression stress path, triaxial compression (CTC) and extension (CTE) stress path test results are used to evaluate the model parameters. The prediction procedures of stress-strain and volume change behaviour followed procedures discussed by Atkinson and Bransby (1978) and Desai and Siriwardane (1984). From the model parameters, it can be seen that the slope of critical straight line $(M)$ increases with the use of reinforcement. This is due to the effect of additional equivalent confinement that increases the strength of the soil composites. The consolidation parameters i.e. slope of the normal consolidation line $(\lambda)$, and the specific volume change at critical state line $(I)$ have to slightly higher values than unreinforced soil. The values are also dependent on the types of reinforcement. On the other hand, the slope of the swelling line $(\kappa)$ and Specific volume $(v)$ shows marginal variations. The Cam-Clay model parameters for the unreinforced and reinforced soil are presented in Table 1.
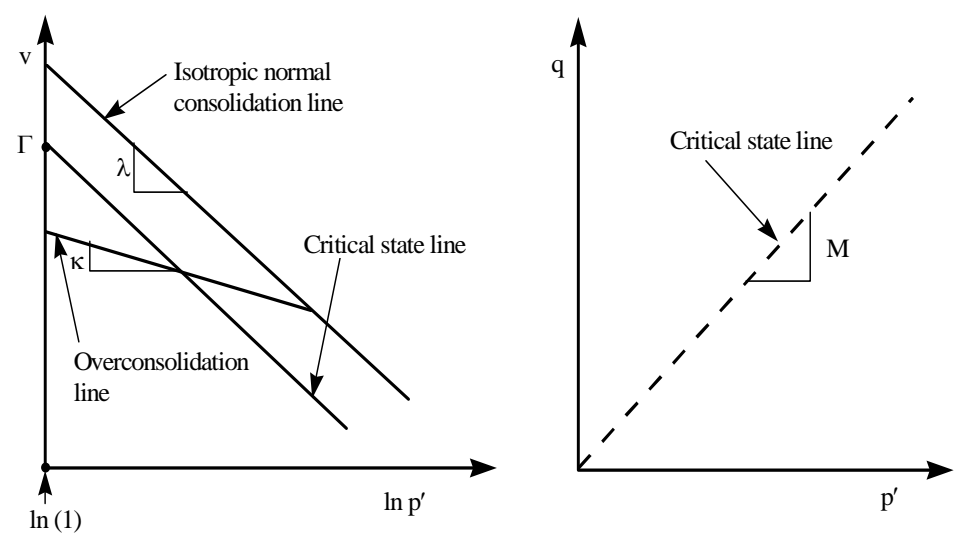

Fig.8. Definition of model parameters for Cam-Clay 
TABLE 1. Cam-Clay model constants for unreinforced and reinforced residual soil

\begin{tabular}{|c|c|c|c|}
\hline $\begin{array}{l}\text { Stress } \\
\text { Paths }\end{array}$ & Model constants & $\begin{array}{l}\text { Unreinforced } \\
\text { soil }\end{array}$ & $\begin{array}{c}\text { Reinforced } \\
\text { soil }\end{array}$ \\
\hline \multirow{5}{*}{ 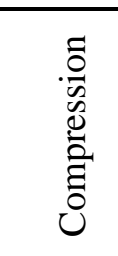 } & Critical state line slope $(\mathrm{M})$ & 1.11 & 1.30 \\
\hline & Swelling line slope (к) & 0.011 & 0.020 \\
\hline & Normal consolidation line slope $(\lambda)$ & 0.039 & 0.060 \\
\hline & Specific volume at the critical state line $(\Gamma)$ & 2.01 & 2.21 \\
\hline & Specific volume $(v)$ & 0.36 & 0.33 \\
\hline \multirow{5}{*}{ 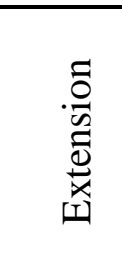 } & Critical state line slope $(\mathrm{M})$ & 0.79 & 0.87 \\
\hline & Swelling line slope $(\kappa)$ & 0.011 & 0.020 \\
\hline & Normal consolidation line slope $(\lambda)$ & 0.039 & 0.060 \\
\hline & Specific volume at the critical state line $(\Gamma)$ & 2.01 & 2.21 \\
\hline & Specific volume $(v)$ & 0.36 & 0.33 \\
\hline
\end{tabular}

\section{PREDICTION PROCEDURE}

The predictions of the stress-strain and volume change behaviour for decomposed granite soils have been made using Cam-Clay model and finite element method (FEM). For Cam-Clay model, the various characteristics are computed herein along with the experimental results. For this purpose, the normality rule was used to derive the incremental stress-strain relations, which can be written as:

$$
\{d \sigma\}=\left[\mathrm{C}^{\mathrm{ep}}\right]\{d \varepsilon\}
$$

where $\{d \sigma\}$ and $\{d \varepsilon\}$ are vectors of incremental stress and strain components, and $\left[C^{e p}\right]$ is the constitutive matrix expressed in terms of the material constants. The prediction of stress-strain for a given stress path, can be made by integrating Equation 1 from the initial stress condition. The stress-strain volume changes behaviour thus obtained are compared with experimental results. For the finite element analysis, Cam-Clay parameters and CAD based software, SIGMA/W, were used for the analysis for unreinforced and reinforced soil.

\section{FINITE ELEMENT ANALYSIS}

An axisymmetric triaxial specimen of diameter $d$ and length $L=2 d$ has been analyzed using the finite element method. Figure 9(a) shows finite element simulation of a cylindrical triaxial test specimen containing only one element with boundary and loading conditions. Using symmetry of the specimen, one quarter of the soil sample was discretised into eight 8-noded solid axisymmetric elements having 37 nodes are shown in Figure 9(b). The initial stresses were applied equal to the consolidation pressures. The conventional triaxial compression (CTC) stress path ( $\sigma_{2}=\sigma_{3}=$ constant while $\sigma_{l}$ is increased) has been simulated at two confining pressures. The load was applied in increment of $10 \mathrm{kPa}$ each, and one iteration was performed for each increment. In the case of TC stress path, the top and bottom faces were loaded in compression and vertical face was loaded in tension. On the other 
hand, for TE stress path, the top and bottom were loaded in tension and vertical face in compression. For other stress conditions, loading was applied according to the stress path followed as described in Figure 1. In case of two layers non-woven geotextile reinforced soil, one quarter part of the sample was discretised into eight 8noded solid elements and four 6-noded interface elements having 47 nodes. Boundary conditions of the discretised reinforced sample were also similar to that of unreinforced soil. The reinforcement was modelled as 8-noded solid elements. Axisymmetric condition was assumed here and uniform pressure loading was applied according to the stress path followed after keeping initial stresses equal to initial consolidation pressures.

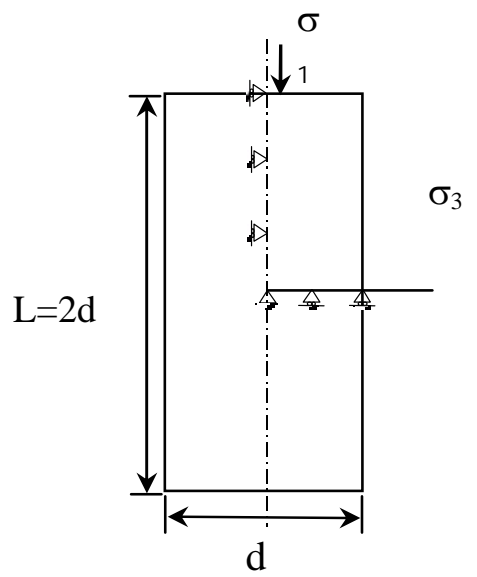

(a)

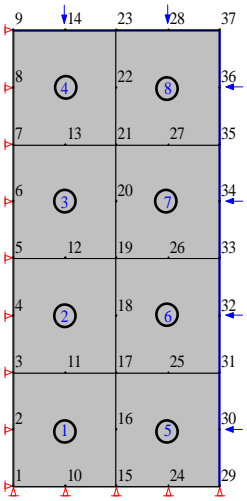

(b)

FIG.9. Finite element (a) formulation (b) simulation of a triaxial test specimen

\section{MODEL SIMULATION AND COMPARISON}

The model simulation and comparison for unreinforced and reinforced soil were made using test data and model constants. The predicted responses of the stressstrain and volume change characteristics using Cam-Clay model constants and finite element method are presented. The foregoing Cam-Clay model constants were used to back-predict the behaviour of the test results at consolidation pressures $\sigma_{c}=200$ $\mathrm{kPa}$ and $\sigma_{c}=400 \mathrm{kPa}$. The comparison between the predictions and the observations behaviour of TC and TE stress paths for unreinforced and reinforced soil are shown in Figure 10 to Figure 13. It can be seen that the correlations between the two test results for decomposed granite soil are satisfactory. Numerical simulations were carried out for the laboratory triaxial stress path tests performed on specimens for both unreinforced and reinforced soil using finite element method. These simulations were done to predict stress-strain response using Cam-Clay model constants. Predictions from finite element method (FEM) using the SIGMA/W are comparatively closer to the observed response than the other predictions. 

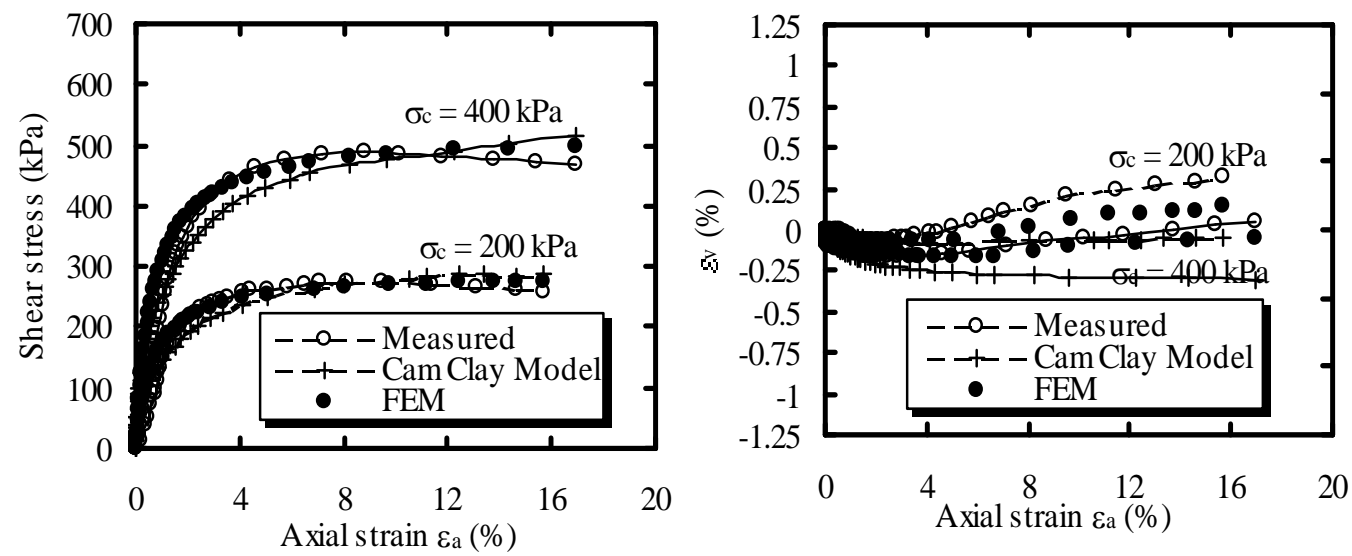

FIG.10. Measured and predicted shear stress vs. axial strain and volume change vs. axial strain characteristics of unreinforecd soil for TC stress path
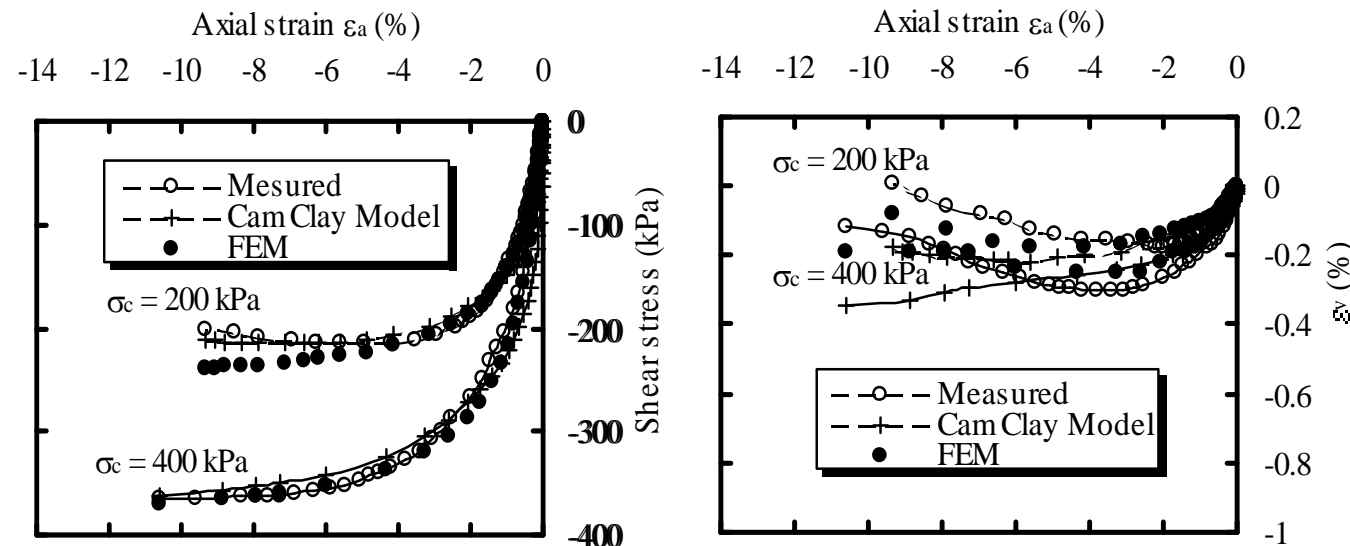

FIG.11. Measured and predicted shear stress vs. axial strain and volume change vs. axial strain characteristics of unreinforced soil for TE stress path
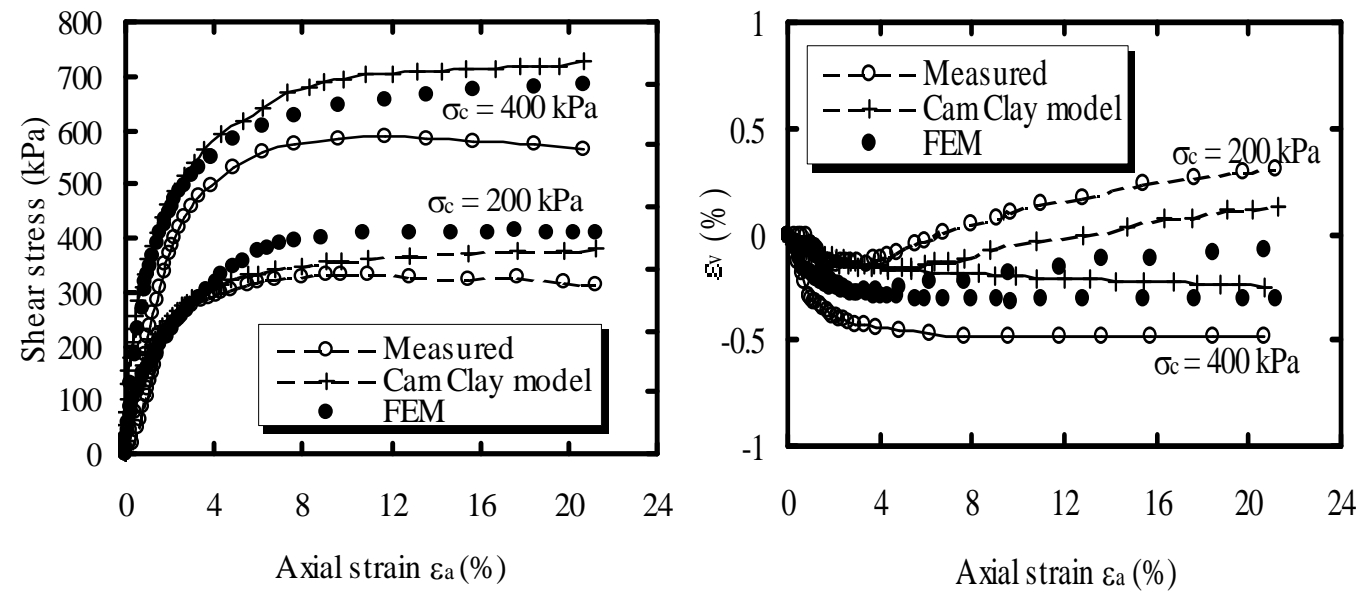

FIG.12. Measured and predicted shear stress vs. axial strain and volume change vs. axial strain characteristics of reinforced soil for TC stress path 

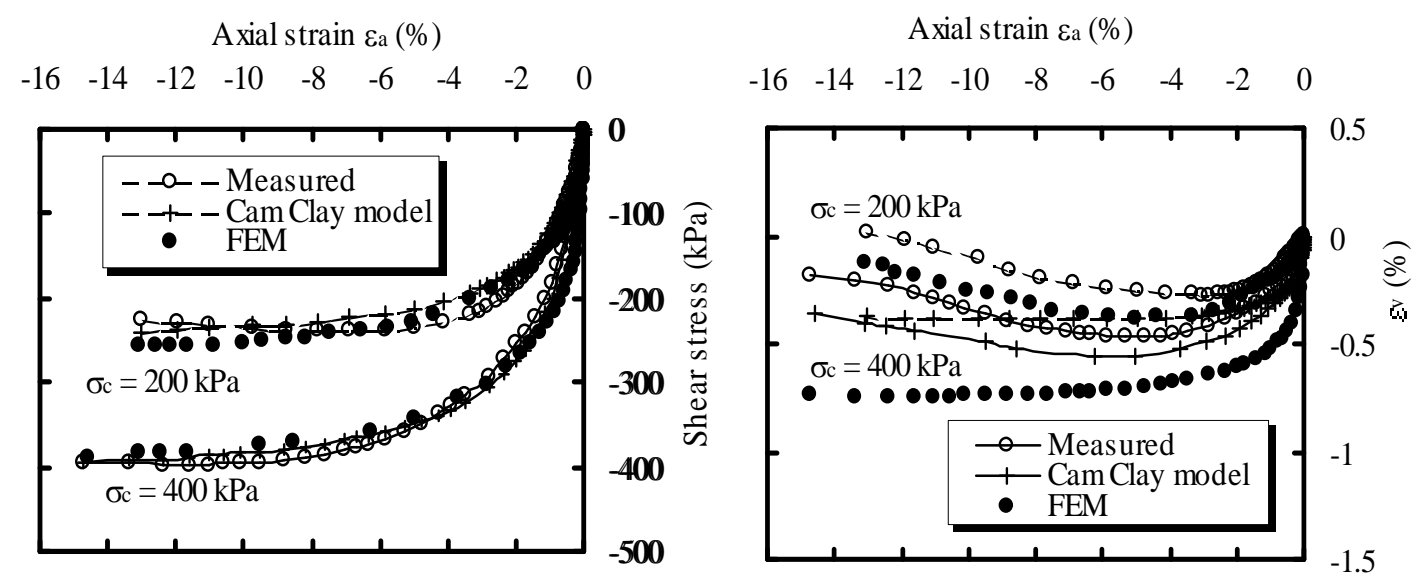

FIG.13. Measured and predicted shear stress vs. axial strain and volume change vs. axial strain characteristics of reinforced soil for TE stress path

\section{CONCLUSIONS}

Brief research summaries of this study and model performance of the stress-strain characteristics of the unreinforced and reinforced residual soil are given. The stressstrain and volume change behaviour for granite soils are highly stress paths dependent. Maximum percentage of increase in the strength exhibits for CTC path and minimum for RTC path. For extension paths, the percentage increase is maximum for CTE path and minimum for RTE path. It is also observed that the percentage increase in the strength is stress path dependent. But the shear parameters of the unreinforced and reinforced soils are independent of the various stress paths followed. The Cam-Clay model, which is based on the theory of elasto-plasticity, has been also used to characterise the behaviour of the residual soil composites. For finite element predictions, the Cam-Clay model constants have been used to simulate the stress-strain and volume change characteristics of the soil. FEM predictions of stress-strain and volume change of soil composites close to the measured response. The model constants obtained from this study can be contributed in the design and analysis of shallow foundations, embankments, retaining structures and stability problems for unreinforced and reinforced residual soils using the finite element method.

\section{REFERENCES}

ASTM 2000. Testing of geotextiles and related products. Annual book of ASTM standard, 04.08.

Atkinson, J.H. \& Bransby, P.L. 1978. The mechanics of soils: An introduction to critical state soil mechanics. UK: McGraw-Hill.

Cui, Y.J. \& Delage, P. 1996. Yielding and plastic behaviour of an unsaturated compacted silt. Geotechnique, 46(2): 291-311. 
Desai, C.S. \& Siriwardane, H.J. 1984. Constitutive laws for engineeing materials with emphasis on geologic materials. Englewood Cliffs, USA: Prentice-Hall, Inc.

Mofiz, S.A. 2000. Behaviour of unreinforced and reinforced residual granite soil, PhD Thesis, Universiti Kebangsaan Malaysia.

Roscoe, K.H., Schofield, A.N. \& Thurairajah, A. 1963. Yielding of clays states wetter than critical. Geotechnique, 13: 211-240.

Roscoe, K.H. \& Burland, J.B. 1968. On the generalised stress-strain behaviour of wet clay. Heyman, J. and Leckie, F. (ed.). In Engineering plasticity, 535-609. London: Cambridge University Press.

Taha, M.R, Mofiz, S.A., Hossain, M.K. \& Asmirza, M.S. 1999. Model simulation of residual soil in triaxial extension tests. Proceedings. of the Fifth Geotechnical Engineering Conference, Geotropika-99, 105-114. 